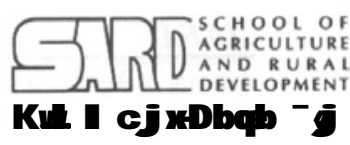

Available online at http://www.banglajol.info/index.php/jard

\title{
Effects of Beta Ratio and Reynold's Number on Coefficient of Discharge of Orifice Meter
}

\author{
M. M. RAHMAN ${ }^{1 *}$, R. BISWAS ${ }^{2}$ \& W. I. MAHFUZ ${ }^{3}$ \\ ${ }^{1,2 \& 3}$ Department of Irrigation and Water Management, Bangladesh Agricultural University, \\ Mymensingh-2202, Bangladesh
}

\begin{abstract}
Orifice meter is a very common flow measuring device installed in a pipe line with minimum troubles and expenses. A coefficient of discharge $\left(C_{d}\right)$ is to be used to get actual discharge from theoretical discharge as different head losses occur in the orifice. An experiment was carried out in the Hydraulic Laboratory of Bangladesh Agricultural University (BAU), Mymensingh to see the variation of $C_{d}$ with beta ratio, $\beta$ and Reynold's number, $R_{e}$. The test was conducted with five orifice plates having beta ratios of $0.30,0.35,0.47,0.59$ and 0.71 installed concentrically in a pipe of $8.5 \mathrm{~cm}$ diameter, flowing water through it. Differential pressure head was recorded by a differential mercury U-tube manometer to calculate the theoretical discharges from Bernoulli's energy equation. It was found that $C_{d}$ had a positive linear relationship with beta ratio where its dependency was stronger on $\beta$ than $R_{e}$ in case of low flow rate with highest value of coefficient of determination $\left(R^{2}=0.8931\right)$ for four-fifth valve opening condition. On the other hand, $C_{d}$ followed a curvilinear (concave) relationship with $R_{e}$ for all beta ratios except 0.47 which showed convex relationship. However, strong relationships with the value of $R^{2} 0.944$ and 0.9563 were found for greater beta ratios 0.59 and 0.71 , respectively. A combined interpretations of experimental data from a bar diagram revealed that orifice meter with beta ratio 0.60 can be used for efficient pipe flow measurement.
\end{abstract}

Key words: Beta ratio, Reynold's Number, coefficient of orifice meter.

\section{INTRODUCTION}

At present, flow measurement is an important and significant task in distributing and regulating the limited but high demandable fluids (water, gases, petroleum etc) in different sectors. Perhaps, most of the fluids with a great utility are transmitted through pipe flow systems because of its suitability, durability and effectiveness. So, an easy, accurate and economical flow measurement technique is expected for better management of fluids flowed through pipes. Several types of devices can be used to measure the flow rate through pipe lines. Amongst various flow measuring devices venturi tube, orifice plate and elbow meter are normally used for their simplicity and low cost. However, orifice meters are becoming more popular in developing countries to measure discharge especially in pipe irrigation projects (Smajstnla and Harrison, 2002). Despite its highest minimum installation troubles in a pipeline, the principal disadvantage of this device is the greater energy losses due to friction, contraction, obstruction, eddies etc. than that of venturi tube or flow nozzle (Daugherty and

\footnotetext{
* Corresponding author: Assistant Professor, Dept. of Irrigation and Water Management, Bangladesh Agricultural University, Mymensingh-2202. Email: mizaniwm@yahoo.com

(C) 2009 School of Agriculture and Rural Development, Bangladesh Open University, All rights reserved.
} 


\section{M. Rahman et al.}

Franzini, 1977). In principle, orifice meter obstructs the flow in a pipe and creates a pressure difference between upstream and downstream of the plate. The Bernoulli's energy (BE) equation is used to calculate the desired discharge. The actual flow profile downstream of the orifice, is quite complex since it flows as jet having no fixed area like the throat of Venturi meter. However, some researchers suggest to take reading at vena contracta, approximately one half the pipe diameter at downstream. The distance and size of the vena contracta are not constant but vary with beta ratio, $\beta$ (ratio of diameter of orifice to pipe) and Reynolds's number, $R_{e}$. The aforementioned problems associated with orifice meter usually overestimate the discharge found from Bernoulli's energy equation. So a discharge coefficient $\left(C_{d}\right)$ is multiplied with theoretical discharge to get actual value. However, $C_{d}$ has no unique value; rather it varies with beta ratio and Reynold's number. For most commercial orifice meters and high Reynold's number $(\operatorname{Re}>30000)$, the value of coefficient of discharge $\left(C_{d}\right)$ is nearly constant, whereas for lower Reynold's number $C_{d}$ varies abruptly. On the other hand, $C_{d}$ increases with the beta ratio for a fixed $R_{e}$, resulting a decrease of differential pressure across the orifice plate. Too much lessening this differential head for extreme beta ratio reduces the accuracy of measurement. For this reason, beta ratio has to be kept to an optimum value. It is suggested that for greatest accuracy the beta ratio should be less than 0.7 (Florida Cooperative Extension Service, Institute of Food and Agricultural Sciences, 2002). Though some researches have been done on the relationship of between $C_{d}$ and $R_{e}$ the combined effects of $R e \&$ $\beta$ on $C_{d}$ are very rare. The objective of this study was to examine the variation of coefficient of discharge $\left(C_{d}\right)$ of locally made orifice meter with different beta ratios and Reynold's numbers.

\section{MATERIALs AND Methods}

\section{Basic concept of orifice meter}

Basically an orifice meter is a circular metallic plate having an opening at its centre installed in a pipe to measure flow rate creating pressure drop across it. Due to the simple construction and installation, the thin sharp edged orifice has been adopted as a standard one. As the fluid approaches to the orifice, the pressure increases slightly and then drops suddenly. It continues to drop until the "vena contracta" and then gradually increases until at approximately 5 to 8 diameters of orifice at downstream. The decrease in pressure as the fluid passes through the orifice is a result of the increased velocity of the fluid passing through the reduced area of the orifice. When the velocity decreases as the fluid leaves the vena contracta the pressure increases and tends to reach to its original level. All of the pressure losses are not recovered because of friction and turbulence losses in the stream. The pressure drop across the orifice increases with the rate of flow. The differential pressure is proportional to the square of the velocity. Applying BE equation at upstream and downstream sections of orifice plate, the following equation can be found to measure the theoretical discharge, $Q_{\text {th }}$

$$
Q_{t h}=A_{2} \frac{\sqrt{2 g \Delta h}}{\sqrt{1-\left(\frac{d_{2}}{d_{1}}\right)^{4}}}
$$

where $\Delta h$ is the differential pressure head, $d_{1} \& d_{2}$ are diameters of pipe and jet at vena contracta, respectively where pressure gauges are installed. Since it was difficult to measure the diameter of the jet inside the pipe, the diameter of the orifice was taken $d_{2}$ and $A_{2}$ was calculated accordingly. For the same reason, location of the vena contracta was approximated at $8 \mathrm{~cm}$ downstream of the orifice plate. While fluid passing through orifice, some irreversible energy is lost due to obstruction, friction, contraction, eddies etc. that causes a higher differential pressure head not responsible for discharge at all. Besides, pressure tapping at downstream in stead of at orifice, may overestimate or underestimate the actual discharge. To consider all these losses in account, the theoretical discharge is multiplied by a coefficient of discharge $\left(C_{d}\right)$ to get actual discharge. So, actual discharge can be expressed as

$$
\mathrm{Q}_{\mathrm{act}}=\mathrm{C}_{\mathrm{d}} \mathrm{Q}_{\mathrm{th}}
$$


$C_{d}$ depends on the ratio of orifice to pipe diameter called beta ratio $(\beta)$ and Reynold's number $\left(R_{e}\right)$ that can be expressed as equation (3)

$$
R_{e}=\frac{4 \mathrm{Q}_{\mathrm{act}}}{\pi \mathrm{d}_{1} \gamma}
$$

Where, $v$ is kinematics viscosity of water at $30^{\circ} \mathrm{C}\left(0.8 \times 10^{-6} \mathrm{~m}^{2} / \mathrm{s}\right)$.

\section{Fabrication of orifice meter}

Five orifice plates having different opening diameter were made by locally available cast-iron steel plate in a local workshop (Fig.1). The diameters of the opening were 2.54, 3.00, 4.00, 5.00 and $6.00 \mathrm{~cm}$ where pipe diameter was $8.50 \mathrm{~cm}$. The orifice hole was perfectly round in the center of the circular steel plate and sharp edged. The plate thickness was about $6 \mathrm{~mm}$ around the circumference of the hole. Circular rubber gaskets were used on both sides of the orifice plate to prevent any unnecessary leakage from pipe.

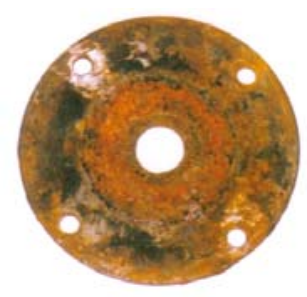

$\mathrm{d}: 2.54 \mathrm{~cm}$

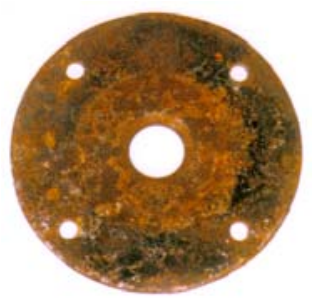

$\mathrm{d}: 3.00 \mathrm{~cm}$

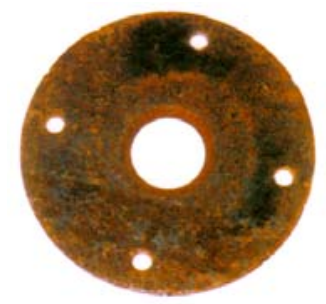

d: $4.00 \mathrm{~cm}$

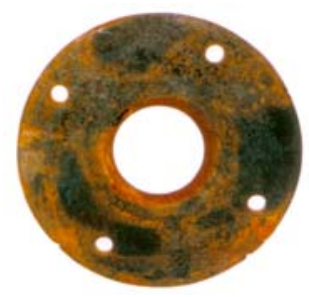

d: $5.00 \mathrm{~cm}$

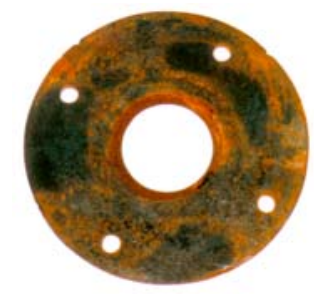

$\mathrm{d}: 6.00 \mathrm{~cm}$

Fig. 1. Orifice meters of different diameter

\section{Experimental set-up}

This study was conducted in the Hydraulic Laboratory of the Department of Irrigation and Water Management of the Faculty of Agricultural Engineering and Technology, BAU. A differential U-tube mercury manometer was tapped at a distance of $10 \mathrm{~cm}$ upstream and $8 \mathrm{~cm}$ downstream of the orifice to measure differential pressure head. Water was pumped by a pump which was operated by a 7.5 horse power electrical motor and required actual discharge was measured by volumetric method. Pipe flow rate was controlled by a discharge valve. Five separate readings of discharge and its corresponding pressure difference were recorded for each beta ratio. The discharge valve was kept at five fixed opening positions and for each valve opening condition, five orifice plates were installed individually and their corresponding discharges were recorded also. In this way, the variation of discharge was ensured solely by different orifice plates for each valve opening condition in the pipe. 
M. M. Rahman et al.

\section{Results AND Discussion}

\section{Effects of beta ratio $(\beta)$ on coefficient of discharge $\left(C_{d}\right)$}

Figure 2 shows the relationship between $\beta$ and $C_{d}$ for different discharges controlled by varying valve opening in discharge pipe.

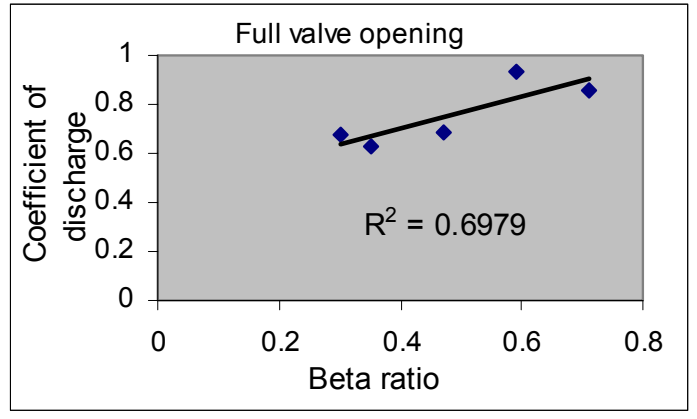

(a)

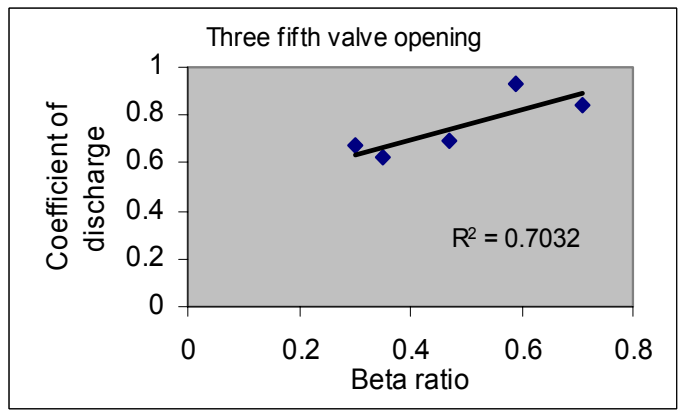

(c)

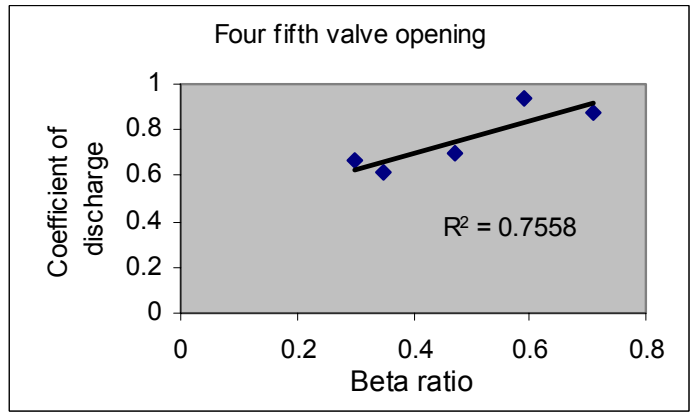

(b)

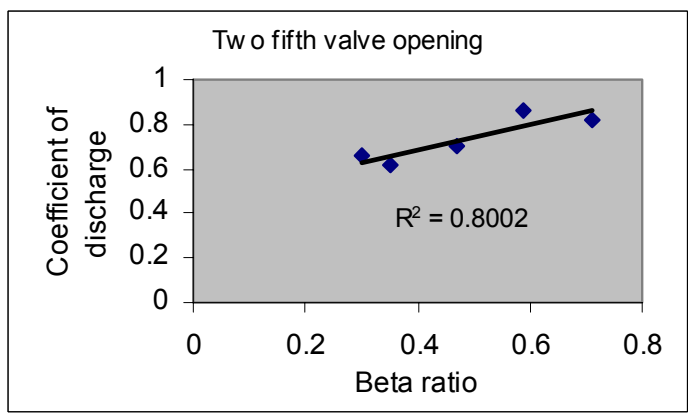

(d)

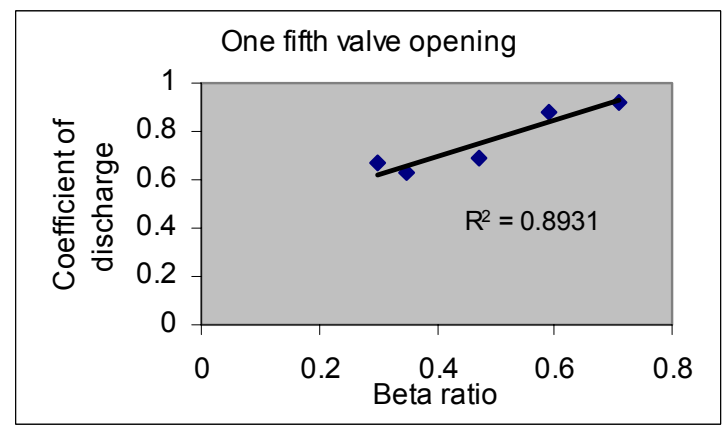

(e)

Fig.2. Relationship between beta ratio and coefficient of discharge

Since in Fig. 2 the relationship is only for a fixed valve opening condition, so definitely the cause behind the changes of $\mathrm{C}_{d}$ is the variation of discharge influenced by the degree of obstruction imparted by orifice plate due to different beta ratios. At every case, $C_{d}$ follows a positive linear relationship with $\beta$ where the coefficients of determination $\left(R^{2}\right)$ are differing rather than identical for five valve opening conditions. The value of $R^{2}$ is increasing with valve opening except for third case (Fig. 2c). However, the highest $R^{2}$ value was found to be 0.8931 for the discharges corresponding to one fifth valve opening condition (Fig. 2e) i.e. when the flow rate was comparatively lower than other valve opening conditions. It can be said that the coefficient of 
discharge is more sensitive to beta ratio in case of lower flow rate. It might be due to the reduction of irreversible losses for lower discharge.

\section{Effects of Reynold's Number $\left(R_{e}\right)$ on coefficient of discharge $\left(C_{d}\right)$}

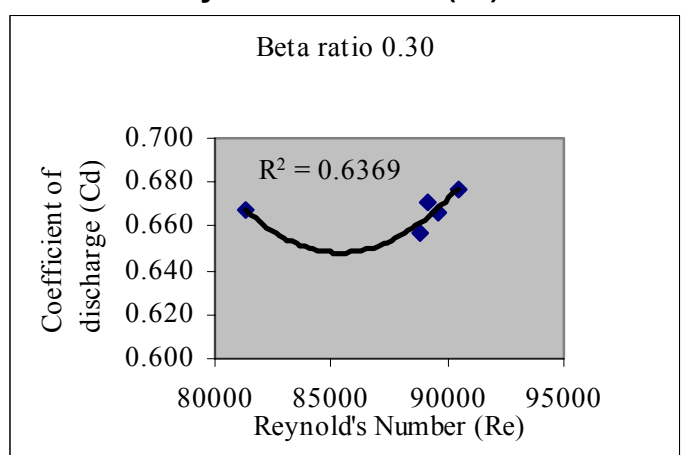

(a)

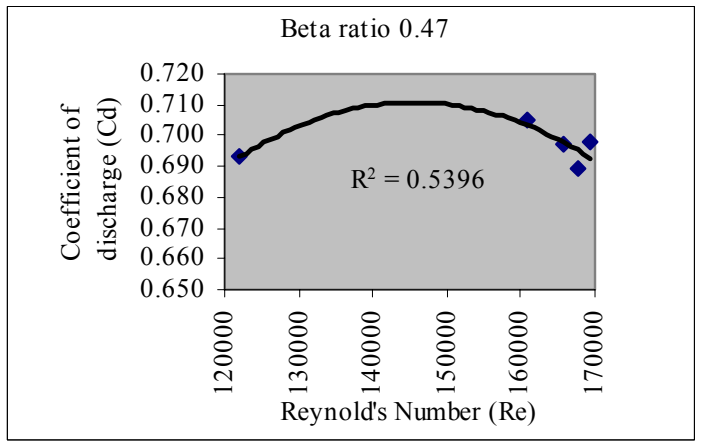

(c)

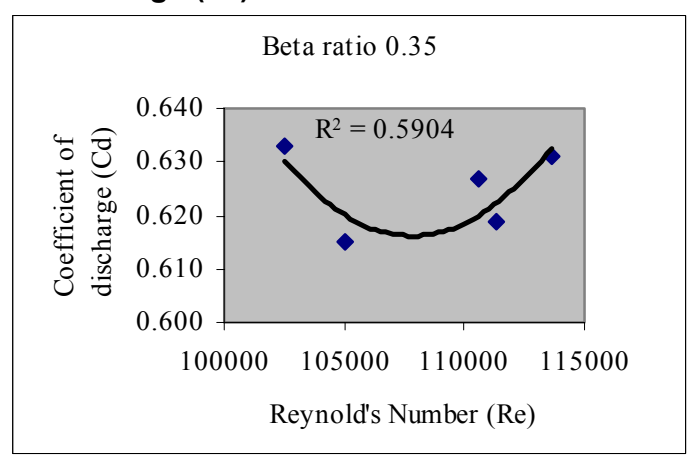

(b)

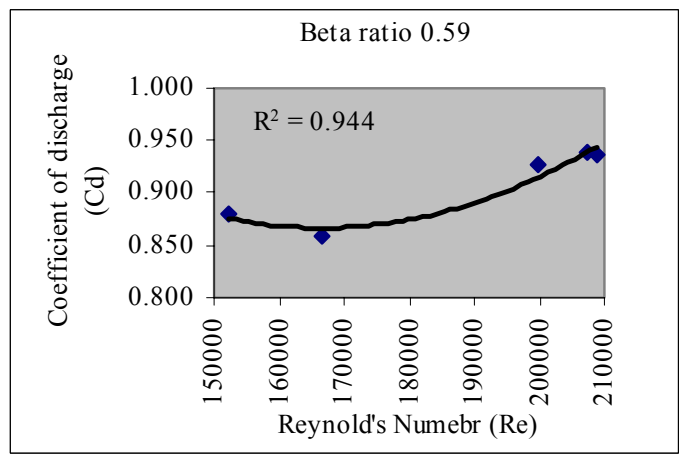

(d)

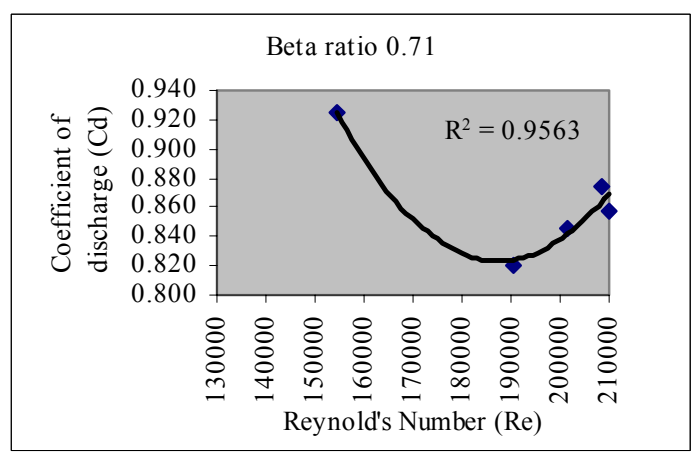

(e)

Fig.3. Relationship between beta ratio and Reynold's number

From figure 3 , it is shown that for each beta ratio a curvilinear relationship exists between $C_{d}$ and $R_{e}$. For the all cases except beta ratio 0.47 , firstly $C_{d}$ decreases with increasing $R_{e}$ until it reaches to a minimum value and then starts to rise again. Stronger relationship can be seen for the higher beta ratio $(0.71)$ with maximum $R^{2}$ value of 0.9563 . However, the value of $C_{d}$ changes rapidly when $\beta$ is 0.71 . Similar results were reported by Smajstrla and Harrison (2002), and Danial (1997). The curvilinear variation of $C_{d}$ may be explained regarding the dominancy of actual and theoretical discharges measured from differential head, $\Delta \mathrm{h}$. It means that the increment of $\mathrm{Q}_{\mathrm{th}}$ is 


\section{M. Rahman et al.}

more than that of $Q_{a c t}$ until $C_{d}$ reaches to a minimum value. Differential head comprises of two components, temporary head loss due to converting potential to kinetic energy at orifice and irreversible losses which is not responsible for actual flow rate at all. It seems, while $C_{d}$ decreasing with $R_{e}$, head losses $\Delta h$ overestimate the theoretical discharge. These findings agree with the result of Daugherty, R. L. and Franzine, J. B. (1977), whose results show that the value of $C_{d}$ drops steadily with $R_{e}$ until reaches to a constant figure. However, unlike Daugherty and Franzines experiment, in the present case $\mathrm{C}_{d}$ follows a step up trend in stead of remaining constant. Reasons behind this finding might be that the losses do not increase as faster as it could be beyond the minimum value of coefficient of discharge, i.e. there would have a critical value of $R_{e}$ for which $C_{d}$ is minimum for an specific beta ratio. However, the behaviour of $C_{d}$ for $\beta$ value 0.47 needs further investigation.

Results from figure $2 \& 3$, reveal that $C_{d}$ depends on both beta ratio and Reynold's Number where former has positive linear relationship and latter has curvilinear relationship. For this reason, there will have an optimum value of beta ratio for maximum $C_{d}$.

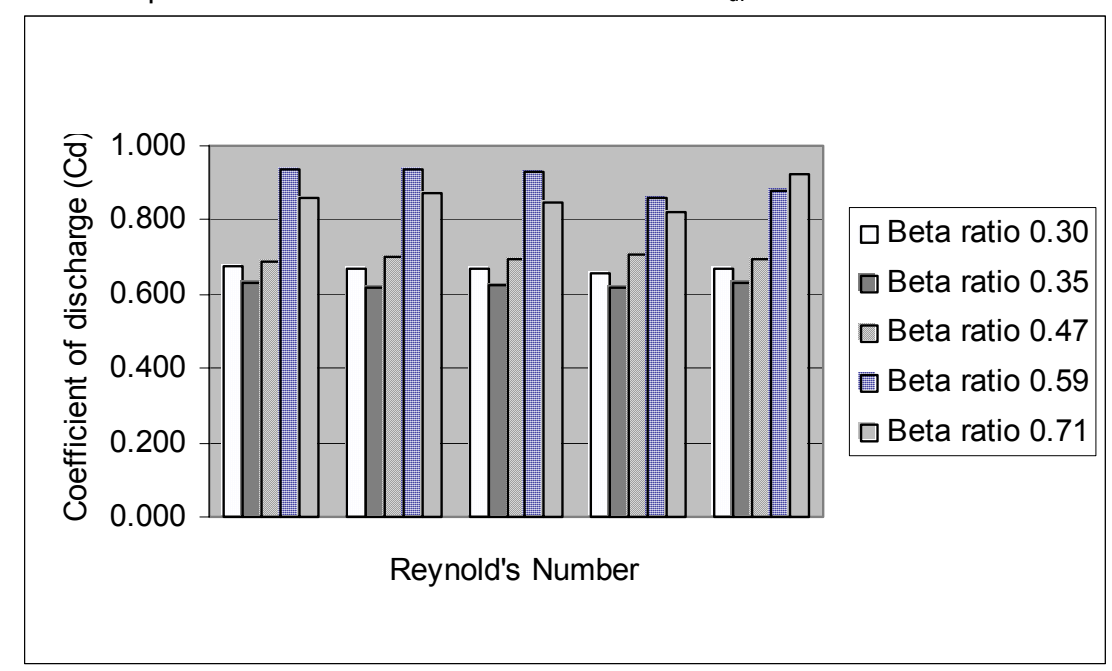

Fig.4. Bar diagram of coefficient of discharge $\left(C_{d}\right)$ for different beta $(\beta)$ ratios

Figure 4 represents average pattern of $C_{d}$ found by changing pipe discharge i.e. $R_{e}$ for each $\beta$ separately. The coefficient of discharge lies within the range of $0.600-0.700$ for first three beta ratios while it exceeds 0.800 for last two $\beta$. Interestingly, despite having linear relationship between $C_{d}$ and $\beta$ (fig.2), the highest average value of $C_{d}$ (about 0.900 ) was found at beta ratio 0.59 (Fig.4) in stead of 0.71 . These research findings confirmed that the coefficient of discharge was affected by both beta ratio and Reynold's Number simultaneously and orifice meter with $\beta$ equal to 0.60 may be used effectively for pipe flow measurement.

\section{LiteratuRE Cited}

Daniel, 1997. Fundamentals of Orifice Meter Measurement. Measurement and Control, Western Hemisphere, Houston, Texas 77224 U. S. A. pp. 1-18.

Daugherty, R. L. and Franzini, J. B. 1977. A text book of "Fluid Mechanics with Engineering Application". MeGraw- Hill publication. pp. 395-396.

Florida Cooperative Extension Service. Document No. AE 22. Institute of Food and Agricultural Sciences. University of Florida, July 2002. <http://edis.ifas.ufl.edu>

Smajstnla, A. G. and Harrison, D. S. 2002. Orifice Meters for Water Flow Measurement. Florida Cooperative Extension Service, Institute of Food and Agriculteral Sciences, University of Florida,Gainesville. <http://edis.ifas.ufl.edu/pdffiles/AE/AE10700.pdf> 